\title{
AN ETHNOGRAPHY OF ENTANGLEMENTS: MERCURY'S PRESENCE AND ABSENCE IN ARTISANAL AND SMALL-SCALE GOLD MINING IN ANTIOQUIA, COLOMBIA
}

Thomas Robertson ${ }^{1} \&$ Trisia Farrelly ${ }^{2}$

\begin{abstract}
This paper describes a 'follow the thing' methodology as applied to an ethnography of entanglements. This methodology allowed for a materially and politically nuanced understanding of Antioquia, Colombia's response to mercury pollution. This pollution primarily originates from the Artisanal and Small-Scale Gold Mining (ASGM) industry where mercury is employed in the gold extraction process. In following the mercury, the authors experiment with an ethnography of entanglements. The paper discusses how they address the current lacunae in mining ethnographies by focussing on mining as 'practice', going past the provision of technical descriptions of mining and ethnographic descriptions of miners to an ethnography of mining. This ethnographic approach considers the politics of materiality and addresses a lack of attention to the impacts of the presence and absence of materials on social life. Various mining practices in Antioquia illuminate how entanglements between miners and mercury have been co-constitutive of particular modes of ASGM. The paper will also provide examples of 'negative mercury entanglements' where efforts have been made to extricate mercury from mining practices. Rather than creating a vacuum, these mercury absences have been generative of new contested symbolic and material arrangements including entrepreneurial and 'responsible' mining, debates over miners' rights, and the creation of new political relationships between ASGM and large-scale mining companies.
\end{abstract}

Keywords: follow the thing; ethnography; entanglements; mercury; mining; artisanal gold mining; small-scale mining.

\section{INTRODUCTION}

What does it mean to conduct an ethnography of entanglements, and what 
might such an ethnography look like? A 'follow the thing' methodology was employed to provide a materially and politically nuanced understanding of Antioquia, Colombia's involvement in the global environmental health problem of mercury pollution from Artisanal and Small-Scale Gold Mining (ASGM). By focusing on the entanglements of miners, mercury, and gold in Antioquia, the current gap in research in this field between technical descriptions of mining, ethnographic descriptions of miners, and miners' practices can be bridged. In reflecting on the 'follow the thing' method, the paper offers critically reflexive considerations of current debates about what 'ethnography' is/is not. This article offers a somewhat novel ethnographic approach to mining.

Specifically, this article will be based around a description of the nature of entanglements between miners and mercury in Antioquia Colombia. This includes negative entanglements where mercury is absent. We will discuss the generative role mercury's entanglements have had in constructing an informal, small-scale, and mobile mining industry in Colombia. This paper will show how attempts to eliminate mercury's use have resulted in a significant shift in the structure of the ASGM industry. For miners, working without mercury has meant new types of knowledge, new environmental worldviews, the engagement of new actors, new bureaucracy, a more entrepreneurial approach to mining, and working relationships with large scale mining companies. These changes are political in nature, and are enmeshed in debates around the rights of miners and a discourse emphasising ASGM as a 'responsible' industry.

MERCURY POLLUTION: A GLOBAL ENVIRONMENTAL PROBLEM

Mercury pollution is a serious global environmental problem, with the levels of mercury in ocean water shallower than 1000 metres having tripled due to human activity (Lamborg et al. 2014). Mercury is a highly toxic substance which poses a severe risk to human health, and ASGM is the primary human source of this contamination (UNEP 2013). Mercury can form an amalgam with gold, providing a cheap and easy mode of gold extraction without advanced technological capacity, making it ideally suited for ASGM. ASGM is commonly defined by the following features: labour intensive, lacks advanced technology or industrial mining equipment, and uses mercury for gold extraction (Barry 1996; Eftimie et al. 2012; Hinton, Veiga, and Veiga 2003; ILO 1999; UNEP 2006, 2012). ASGM is also typically 'informal', with 'informal' referring to mining which exists between illegality and legality. In Colombia, Echavarria (2014) defines informal mining as mining conducted without a mining title (a legal requirement), often as a traditional activity, but is not associated with illegal armed groups (criminal mining). Siegel and Veiga (2009) prefer the term 'extra-legal' 
to refer to mining that is based around customary practices and exists outside the mainstream legal and economic systems. Following these definitions, here we use 'informal' to refer to mining conducted without a mining title. While it is acknowledged that this type of mining is not carried out within the parameters of the Colombian legal system, ASGM as an informal mode of mining cannot be considered illegal, due to customary rights and traditions, and the weak reach of the legal system in many ASGM areas.

It should be noted that there is wide global variation of activities described as ASGM, with some mines employing large numbers of people or heavy machinery. In some countries such as Mongolia, ASGM is essentially formalised (SDC 2016). Urán (2013) provides a useful proposed typology of a range of mining types under the ASGM label within Colombia, and Tubb (2015) offers a strong anthropological description of relations between groups of miners of different scales in Colombia. This is made possible by thinking beyond ASGM as a unified category. Despite the generally small scale of the mining activities, ASGM is significant in relation to the gold mining industry as a whole. ASGM provides $90 \%$ of all employment in gold mining, a total of some ten to fifteen million people worldwide (UNEP 2012; Veiga and Barker 2004), and produces up to $20 \%$ of the world's gold (Seccatore et al. 2014). While a great deal of attention is currently being paid to the problem of mercury pollution by a range of actors, and despite the signing in 2013 of a global treaty on regulating mercury (the Minamata Convention), concrete solutions to the problem of mercury pollution remain elusive to global regulators.

\section{A ROLE FOR ETHNOGRAPHY?}

One strong emergent trope in the literature on mercury reduction is the need to attend to the social, cultural, political and economic aspects to mercury's use (Clifford 2014; Hilson 2006; Spiegel et al. 2015; Spiegel et al. 2014). While a range of technological methods to eliminate or minimise mercury use exist (Davies 2014; Drace et al. 2012), these have not been widely adopted by miners (Jønsson, Charles, and Kalvig 2013). The inference from these arguments is that if the problem is not technical, then it must be social. However, what this approach might look like remains unclear. This perspective can be critically examined through current trends within anthropology, and the social sciences more broadly.

Bruno Latour speaks to this in the introduction of Reassembling the Social. Here Latour states his intention to 'dispute the project of providing a "social explanation” of some other state of affairs' (Latour 2007, 1). Latour (2007) cri- 
tiques the idea of a 'social dimension', which he describes as an amorphous and elusive field which exists after the subtraction of more tangible fields, namely 'economics, geography, biology, psychology, law, science, and politics' (2007, 3). Latour's work critiques the very basis of the idea of attending to the 'social dimensions' of mercury use. Rather, Latour invites us to attend to mercury use by integrating the social with the material and other tangible fields such as science and politics. Latour's critique can be given extra weight here through a simple thought experiment: mercury is used in over fifty countries across six continents (Veiga, Maxson, and Hylander 2006), with a considerable ethnic, social and cultural diversity across mining communities. This global distribution of mercury use means that to consider it as purely a function of the social, in the sense of it being an idiosyncrasy of particular social groups, is untenable, as it is found in use across a wide range of social types. At the same time, the research, which was conducted from a technical perspective, has established that mercury can neither be considered a purely technical phenomenon (Davies 2014; Drace et al. 2012; Jønsson, Charles, and Kalvig 2013). Instead of purely focusing on the social, Latour instead calls for research that emphasises the tracing of associations. We have taken Latour's statement as a guiding concern toward an ethnographic approach which traces the political, social and material entanglements of Antioquian miners and mercury.

\section{ETHNOGRAPHY AND MINING}

Mining is not a new subject to social anthropology, and a body of relevant ethnographic literature exists to inform this endeavour. Ballard and Banks (2003) for example, provide a review of the anthropology of mining, noting a general shift from a triad model of the state, mining company and community, towards a more complex understanding in which these entities are broken down and treated as non-monolithic. While this review provides a useful starting point, it is focused on large-scale mining which differs in a number of ways to ASGM. For example, ASGM is seldom associated with corporations, and ASGM miners are often community members. As ASGM is generally small-scale and informal, the state is seldom able to exert power over it in the same way as it can with large-scale mines.

Anthropologists have written a range of excellent ethnographies of miners. These include studies of gender (both feminine and masculine) (Bryceson, Jønsson, and Verbrugge 2013; Cohen 2014; Cuvelier 2014), friendship (Grätz 2004), morality (Grätz 2009), perceptions of risk (Soemarwoto and Ellen 2010), decision making (Tubb 2015), the relationship between mining and state formation (Verbrugge 2015) and mining as an economic livelihood (Heemskerk 
2002). However, there is a limited consideration of mining as a practice. Perhaps Taussig's (2004) 'My Cocaine Museum' is an exception in that it considers the experiential nature of mining, although in a manner that is different to the way we apply practice here. Tubb's (2014) work differentiates different types of ASGM, and explores how relationships between groups of miners were closely linked to the types of mining conducted. Tubb's work is a serious consideration of the material conditions of mining, a valuable contribution to this field. Jacka (2015) also contributes in this regard through a study of large-scale mining (the Porgera mine in Papua New Guinea) by applying a political ecology perspective to the mutual constitution of mining, ecology and community. Hilson's (2006) Mercury: An Agent of Poverty in Ghana's Small-Scale Gold-Mining Sector?, while not ethnographic, is one of a small number of research projects that consider mercury as generative of social arrangements, a perspective we develop here. While recent progress is being made towards an anthropology of mining as a practice, most ethnographies primarily have offered close examinations of the lives of miners. Critical ethnographic analyses of the practices of mining can reveal the complex relationships between miners and mercury that may not emerge through ethnographies lacking this particular focus.

\section{FOLLOWING THE THING}

A 'follow the thing' methodology was broadly adopted to understand mercury use as a phenomenon of the miner/mercury entanglements. While mercury as a non-human material guided the research, the research focussed on mercury's entanglements rather than mercury itself. Although mercury was not endowed with the status of research participant, the agency of mercury is core to the study. This builds on current trends in 'follow the thing' methodologies, and connects with a 'new materialisms' theoretical perspective. Our treatment of mercury could also be understood in relation to Marcus' (1995) 'tracking strategies'. The materiality focus employed here takes a 'following the thing' approach, rather than the 'following the commodity' approach of Mintz (1985) or Appadurai (1996). In employing the 'follow the thing' approach, we were able to focus on the materiality of mercury that exists beyond the world of human experiential perception.

To understand the nature of these entanglements, we draw on a loose collection of theories collectively known as 'new materialisms'. The new materialisms perspective includes thinkers such as Karen Barad, Jane Bennett and Tim Ingold, and can be described as a movement that critiques anthropocentric sciences and that attend to material agency (Connolly 2013). The new materialisms differ from actor-network-theory due to their greater focus on relationships 
rather than the entities that are related. In addition, the new materialisms typically view agency as an emergent property of an assemblage, rather than something that is distributed across a network. Borrowing from Barad (2007), we were interested in the way entangled entities act through each other, rather than entities acting on each other. Applying this relational ontology allows us to conceive mercury pollution from ASGM, and to a large extent ASGM itself, as a phenomenon resulting from a complex entanglement, in which mercury, miners, and gold were primary threads.

\section{FIELDWORK}

The fieldwork for this research was conducted in Antioquia, Colombia over a three-month period in 2015. Mercury pollution is normally described as a global environmental problem, which immediately raises anthropological questions such as, 'where is the global?' While the global might be the spatial distribution of mercury, ASGM is situated in the local. Antioquia is an exemplary local manifestation of the mercury pollution phenomenon. In 2011, Colombia was named the worst mercury polluting nation per head of population, contributing up to $20 \%$ of global mercury pollution from ASGM (Cordy et al. 2011; UNEP 2013). Antioquia, the gold mining hub of the nation, has been seen as disproportionately responsible (Cordy et al. 2011; Giraldo-Ramírez and MuñezMora 2012). Mercury levels in several regions of Colombia have been tested at levels that greatly exceed wHo guidelines, with negative health effects observed (Cordy et al. 2011; Cordy et al. 2013; Olivero, Mendonza, and Mestre 1995). Gold mining in Colombia is predominantly informal, with a 2013 estimate that $87 \%$ of mines did not have a mining title (Güiza and Aristizábal 2013). While there have been a number of campaigns to formalise ASGM in Colombia by encouraging ASGM to apply for titles, these have generally been unsuccessful due to a lack of legal differentiation between the requirements for small and large-scale mining and a lack of untitled areas (Güiza and Aristizábal 2013).

To its credit, Antioquia has been proactive in reducing mercury pollution, and can now proudly claim the first instance of large-scale mercury reduction in the world (García et al. 2015). This has primarily been achieved through the Colombia Mercury Project: a fixed-term collaboration between local and international universities, regional and national government, and non-government organisations (NGOs). Working to minimise rather than eliminate mercury use, the project has involved education initiatives, the distribution of new technologies, and technical demonstrations. This has occurred alongside an increase in enforcement of mining legislation, an increase in the price of mercury, and the use of the extraction facilities of large-scale mines by ASGM. An estimated 63\% 
decrease in mercury pollution in Antioquia (a total volume of 46-70 tonnes) has been attributed to the efforts of the Colombia Mercury Project (García et al. 2015). Legislative action has also been taken against mercury, with a law passed in 2013 that will ban mercury use in ASGM by 2018 (El Congreso de Colombia 2013), although it remains to be seen whether this can be enforced. While mercury pollution has been significantly reduced, its total elimination is yet to be achieved, and the full implications of these interventions are not yet understood.

I (Thomas) conducted fieldwork in Antioquia over a three-month period in 2015. ${ }^{3}$ I had visited Antioquia twice previously, for social reasons, and had a familiarity with the region, a strong network of contacts and a working proficiency in Spanish. Using these contacts, as well as some cold calling, I was able to make a range of connections with those working in the formal sector with an interest in ASGM. I made a number of contacts with academics, journalists, and NGO workers (including members of the Colombian Mercury Programme). These contacts led to meetings with gold miners and processing workers in the informal sector through a snowballing approach.

The miners and processors with whom I formed my principle relationships with were all 'non-ethnic' men. Non-ethnic is a problematic term employed in the Colombian census to describe people of mixed-ethnic origin who did not identify as Indigenous or belonging to another minority group. This is significant as, while the government has made progress in recognising the rights of Indigenous groups, non-ethnic Colombians are often denied traditional rights, including access to land and other natural resources (Rivera-Sotelo 2012).

While gender was not a specific focus of this research, it was not easily ignored. ASGM in Antioquia is a masculine space. This does not mean that it is exclusively masculine, as I was introduced to women who were involved in the mining industry, but this always came with an explanation: 'She has to do this job because her husband abandoned her and the government won't support her. It's terrible, she shouldn't have to do this..., or 'Most mines wouldn't hire a woman, but we are different, and more progressive. We like a woman's touch'. This shallow observation fits with the work of Cohen (2014) who described how women could transgress gender roles to participate in the masculine space of mining in Antioquia. However, to do so, women had to appeal to the regional work ethic while complying with all other gender roles. It should be noted this gendering of space is regional and that ASGM is not a universally masculine activity. Antioquia is generally described as having a conservative attitude towards gender roles (Cohen 2014), whereas, even in the neighbouring 
Chocó region, alluvial ASGM is often a feminine activity (Taussig 2004), and an estimated $30-40 \%$ of all artisanal gold miners worldwide are women (Hinton, Veiga, and Beinhoff 2003).

I entered the field with a number of identities, many of which were very different from the miners and processors who I was talking to. I am a university educated, English speaking European New Zealander from a middle-class background. My participants were working class Spanish speaking Colombians, often with limited education and who had not travelled beyond Colombia. While all of my participants involved in 'hands-on' gold mining/processing shared a masculine gender identity, this was often expressed differently. Despite these differences, miners were mostly happy to talk to me, and did not do so from a marginal position. While I had wondered what the reaction to my education would be, I was generally perceived accurately as someone interested in mining, but not an expert, and that they would have to explain things to me from first principles. People seemed initially interested in talking to me for two reasons (implicit in some cases, but often explicitly raised by them): they were artisans who took pride in their work, and therefore enjoyed talking about it to someone who was interested, and secondly, talking to me was a political act (as was everything about ASGM in Antioquia it seemed). A recent police crackdown had meant that these miners, who self-identified as traditional miners, were now being branded as criminals, a classification they considered highly offensive. They saw talking to me as an opportunity to express the ways they self-identified, namely as good citizens.

I conducted fieldwork in three different towns in Antioquia: Caucasia, a bustling agricultural and placer (alluvial) mining town of around 80,000 people, set in lush grassland and swamps, where I spent most of my time; Segovia, a historic town of 50,000 people completely orientated around mining, further up in the highlands, and with a distinctly rough feel, where I spent a moderate amount of time; and in El Bagre, set deeper in the jungle, a relatively recent town completely dedicated to mining. El Bagre is even rougher that Segovia, with a distinctly 'Wild West' atmosphere. This 'Wild West' feeling is justified: ASGM areas are often described as frontiers (Cohen 2014; Serje de la Ossa 2005), and state absence and formation is a contemporary reality which is captured in ASGM literature (Siegel and Veiga 2009; Verbrugge 2015). I travelled to these towns from Medellín, where I was loosely based. Medellín is the populous and industrial regional capital where the relevant NGOs and government departments are based, as well as most of my pre-existing contacts. 


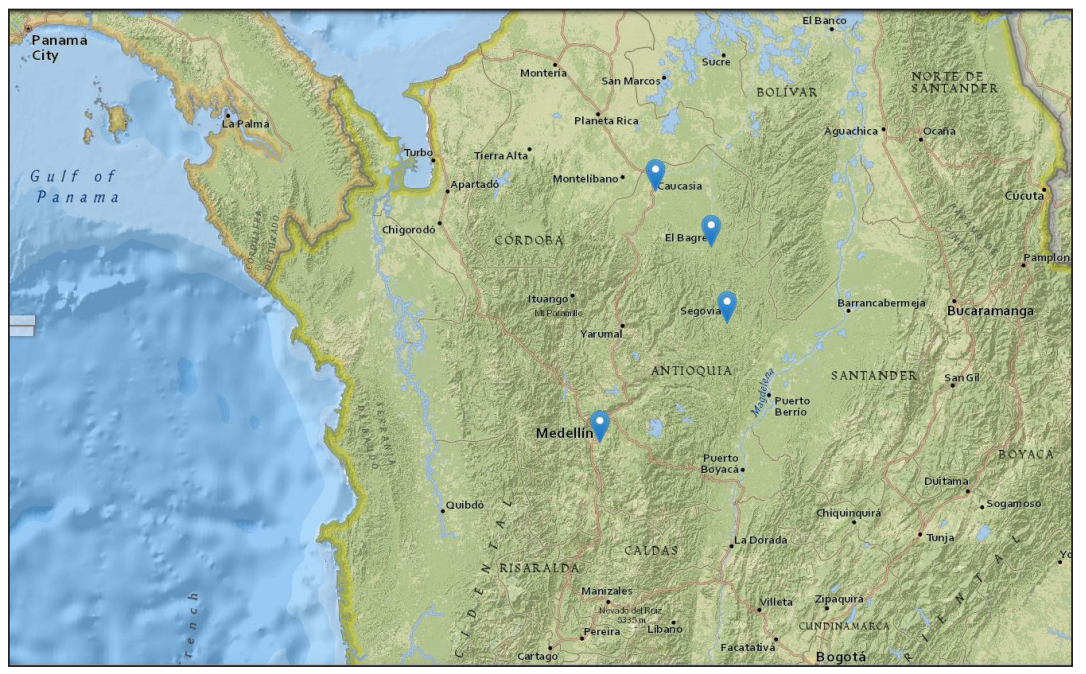

Figure 1. Map of Antioquia, with fieldwork locations marked (Created using the National Geographic map maker, National Geographic n.d.).

The research was primarily conducted through interviews, although these were always seen as part of a wider relationship between researcher and participant. Unfortunately, participant observation was not a practical option here. This was largely due to safety concerns. Safety must be taken seriously in Colombia (although these concerns are often overstated). As many of the mines were located in areas under paramilitary influence, spending time in the mines was not a safe option. However, as most miners took their ore to mining towns for extraction, this gave me the opportunity to talk to miners in an urban setting. I did spend time observing the activities of processing workshops, but the toxic nature of mercury meant participation was not possible. This left me with 'purposive observation' (Stewart-Withers et al. 2014), a term currently absent in anthropology literature which describes unstructured, purposeful observation and 'hanging out' without actively participating.

This inability to conduct participant observation did detract from ethnographic richness, and the work of Tubb $(2015,2014)$ in the Chocó demonstrates the power of participant observation for understanding ASGM. I was also aware that aspects of miners' lives were simply not open to me. For example, miner cosmology has formed a major part of some anthropological accounts of mining (i.e. Golub 2014; Taussig 1980). There were a number of events that indicated that cosmology had an impact on the lives of miners who I was talking 
to (particularly those in underground mining). A public example of mining cosmologies is the statue in Segovia of a miner working below a naked and chained figure I was told represented Mother Earth (Figure 2). However, I felt that due to the nature of these beliefs, I would have to observe mining from within the mines to understand it, and that interviews alone would be unsatisfactory. While participant observation is powerful, recent work has progressed the idea that ethnography does not always require participant observation, and that ethnographic approaches can be made through a variety of other methods (Hockey and Forsey 2012; Okely 2015). Ethnographic interviews can allow participants to guide the direction of the interview. While I was focused on the general theme of mercury, it was the miners who took the lead in explaining how mercury related to themselves and to mining as a whole, a technique which proved effective. Finally, interviews were never isolated events. Rather, they were part of a broader 'hanging out' and relationship building.

ENTANGLEMENTS OF MINERS AND MERCURY ('S ABSENCE)

Our purpose from here is to identify specific entanglements of miners and mercury across several different cases. As stated, mining as an activity is het-

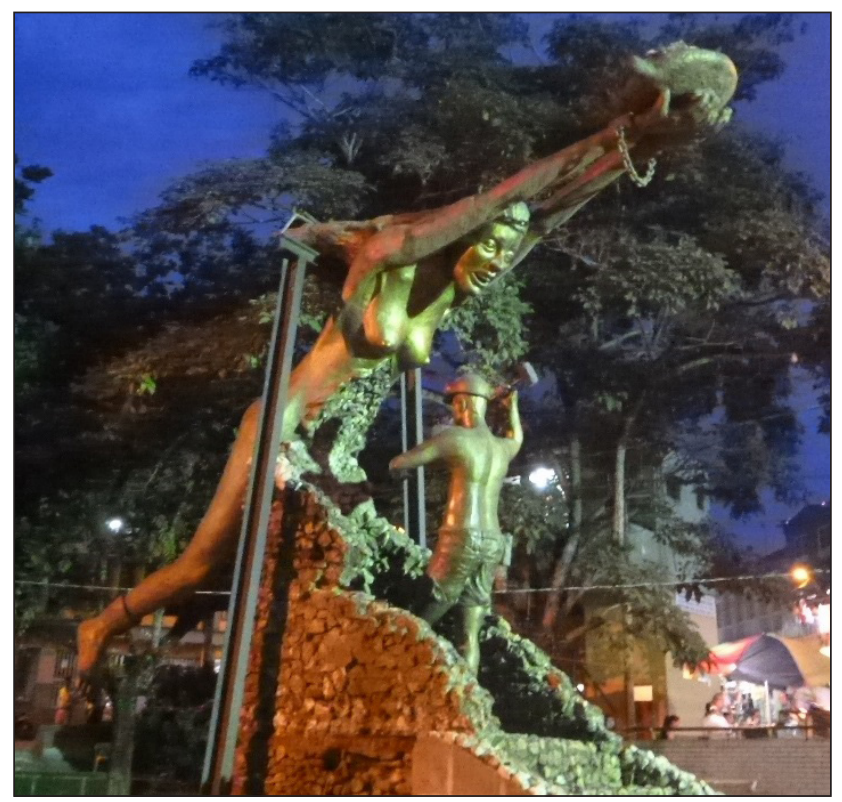

Figure 2: Monument in the central plaza of Segovia. 
erogeneous, as are miners, and thus the specific ways in which mercury is entangled varies. Our goal is to describe how entanglements of materials and people, principally miners, mercury and gold, have generated a particular type of mining which has become the mainstream in Colombia. As miners begin to eliminate their use of mercury, mercury's absence has begun to generate new types of mining. Whether or not these new types of mining become the mainstream remains to be seen, but what we can assert is that the questions of whether they do and whether mercury is eliminated from all mining practices are intimately linked.

A common theme underlying much of this is temporality. ASGM in Colombia is currently in a period of flux, and this flux is both a cause and an effect of mercury reduction (among other factors). All the miners I met were in some way negotiating these changes. The past and present coalesced at the time of fieldwork, with the past constructed as a period of continuity and tradition, and the future offering the possibility of a bright vision of responsible mining, but with the potential demise of ASGM an omnipresent fear.

\section{DREDGE MINING WITHOUT MERCURY-GOING AGAINST THE GRAIN}

We will start our discussion with an exceptional case. Carlos, a dredge owner living near Caucasia, has worked as a miner for decades across Colombia. He had acquired a dredge which he worked with one other man. The dredge is a fairly basic affair: a few plastic barrels held together by a welded metal frame, a tarpaulin cover overhead, a small motor for the dredge, and a long sluice box hanging behind. His operation is nomadic, as he travels up and down the river in his dredge, following the shifting gold bearing sands. He previously used mercury on his dredge, as he would suck up gold bearing sands from the river and wash them on a sluice. Under the sluice were cloth bags bearing mercury. The heavier gold would sink to the bottom of the sluice, and become trapped in the mercury, forming an amalgam. This was conducive to Carlos' lifestyle. He saw himself as a subsistence worker, operating on a week by week basis. He had no major investment in mining or extraction equipment (the dredge being of minimal cost), little engagement with flows of capital or business planning, and yet, thanks to mercury, he was able to extract reasonable quantities of gold. The downside of this was the excessive amount of mercury flowing into the stream, which Carlos had not realised to be problematic (mercury's entanglements exist beyond human perception). When the Colombian Mercury Project visited his village and talked about the problem of mercury pollution, Carlos was shocked, but unsure what to do: 'When they told us we couldn't use mercury, I thought the mining was finished, because if we can't use mercury, how 
could we extract gold?' Nevertheless, while mercury-free mining was then an unknown, he decided to act.

Carlos took the initiative and decided that he would try to work without mercury. This reflected a personal and ethical commitment to the environment and his children who would inherit it. He approached an NGO which specialised in assisting miners with mercury reduction, in accordance with the Minamata Convention. The NGO agreed to provide the miners' association of his town with a set of gravimetric equipment ${ }^{4}$ (some pictured in Figures $3 \& 4$ ), for which Carlos was responsible. Without mercury, this gravitational extraction became rather more technical than his previous method, with far more variables for the equipment depending on the nature of the sand and gold. It also gave Carlos a fixed plant, which he had not had before. All of the town's miners have permission to use this plant. While Carlos had learned about mercury through hands-on experience, he now had to learn how to use the gravimetric equipment through a more formal education with university-educated mining engineers who employed 'scientific' skills. He had to learn new principles of extraction, and struggled to convince other miners of their efficiency. He had

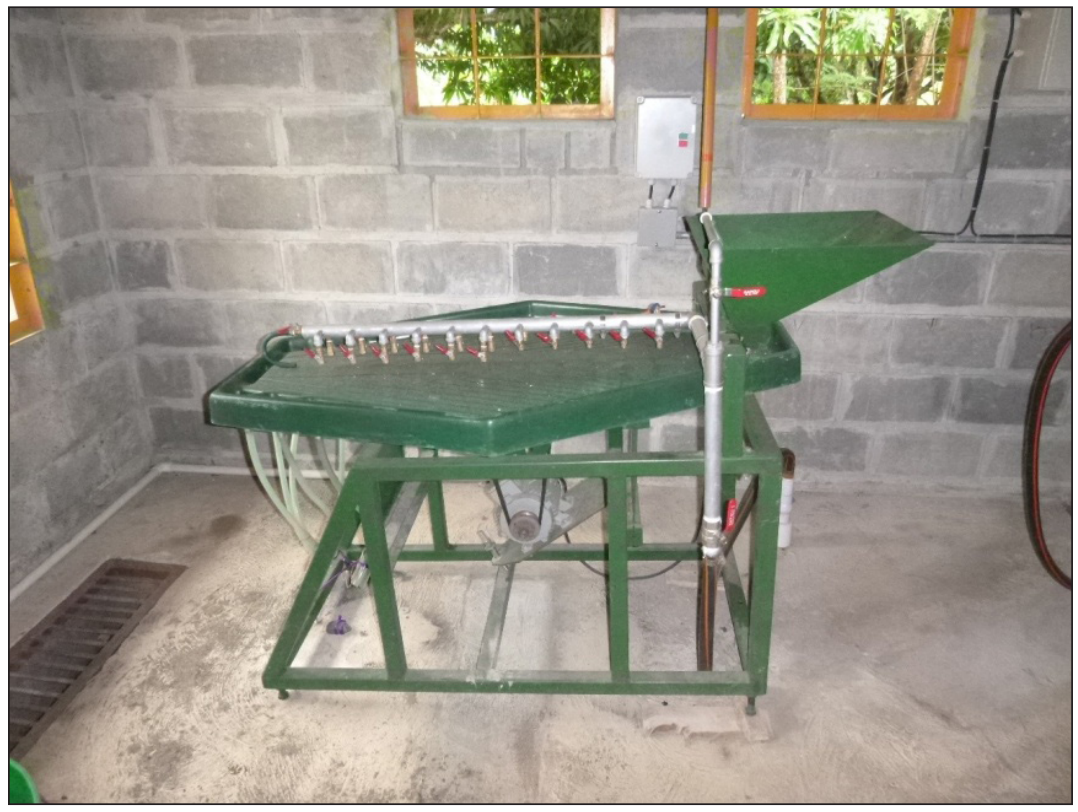

Figure 3. Carlos' trommel for rough gravitational extraction. 


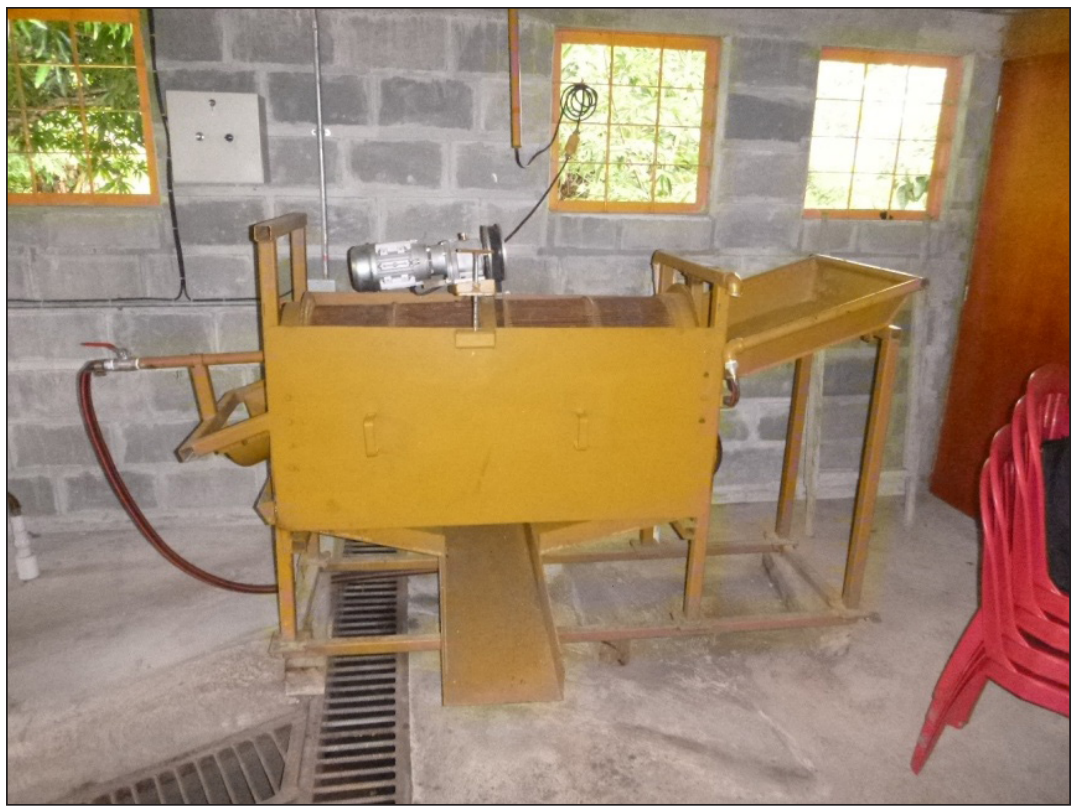

Figure 4. Carlos' Gemini table for finer gravitational.

to consider new business principles, as he found himself responsible for capital equipment, even though he had not purchased the equipment himself. All this represented a fundamental change in the way he approached mining. He rose to what he described as a great challenge and, with assistance, he succeeded in mining gold without mercury.

We describe this situation as going 'against the grain'. While it is admirable from an environmental perspective to mine without mercury, it conflicts with existing structures so that it does not seem tenable as a solution for widespread application. Carlos does not have a mining title and cannot realistically obtain one. Mining titles are provided for fixed areas, while his nomadic dredging operation follows shifting gold bearing sands and cannot easily be contained within a fixed boundary. As there is no provision for ASGM in the legislation (particularly ASGM that uses mechanised equipment like dredges), Carlos would have to go through the same application process as a multinational firm. Carlos does not currently have the capability to undertake this highly bureaucratic exercise, and the expense of this would be greater than what his operation could justify. Furthermore, the police had begun a major crackdown on miners without titles. 
While this is a concern for most dredge owners, many are afforded a degree of protection as their nomadism and lack of seizable equipment, makes it harder for the police to enforce the legislation.

This means that for Carlos, a fixed plant could be considered a liability. The NGO's provision of a fixed plant to Carlos falls into a legally grey area: if Carlos is charged as acting illegally by mining without a title, the NGO could be implicated for aiding an illegal activity. The NGO in question is aware of this problematic aspect and has negotiated it as best they can, as achieving their mandate of mercury reduction is not feasible otherwise. Furthermore, it is not economically viable for NGOs to provide direct assistance for small scale producers (Veiga 2015). Without the NGO's donation of equipment, acquiring the $\$ 10,000$ USD equipment necessary to operate a mercury free mining operation would be unattainable for Carlos. In addition, many ASGM miners have no access to formal modes of lending. Previously, Carlos' ability to obtain credit came from his gold buyer who was also his mercury seller, but as he had ceased to purchase mercury, this credit was no longer available. Finally, even if other dredge miners could invest in a fixed plant, the equipment is only marginally more efficient than mercury (M. Veiga, personal communication, 2015) and thus not cost-effective. While ethically admirable, Carlos' work with the NGO to establish a mercury-free dredge mining system would not prove highly effective. 'Effectiveness' here refers not to gold extraction efficiency (although this is a contributing factor), but exists as a holistic concept that includes the particular situation and capability of miners, and the economic, social and political value miners wish to produce. In other words, effective strategies are those that work in a particular context. The lack of effectiveness of mercury-free dredge mining is not because this practice is inherently non-viable, as the largest mining company in Colombia is a dredge miner (Mineros S.A.S), but because of the small scale of Carlos' mining operation. Carlos' original nomadic, mercury entangled mining operation was effective in its particular context. That is, the change to mercury-free mining was not effective. While Carlos persevered due to his environmental consciousness, a commendable effort, mercury-free mining is not effective in an informal context, in part because mercury is constitutive of informal mining practices.

\section{INCREASING PLACER MINING SCALE: NEW FRONTIERS}

Two miners who began actively engaging with the issue of scale were Esteban, a mine owner near Caucasia, and his right-hand man Miguel. Esteban's operation follows the course of an old river bed, where alluvial gold has accumulated. The operation takes the form of a large pit, with the mining front progressing 
along the old river bed in one direction, and backfilling behind them. The mine employs sixty workers, five excavators and three tip trucks (a very different operation to Carlos' two-man dredge). Previously, the mine used massive quantities of mercury. In the earlier operation, the earth dug from the pit was washed along sluices with bags containing mercury at the bottom. Up to nine kilograms of mercury used to be added to these sluices daily, and while it is unclear what portion was lost to the environment, this is still a considerable quantity. This process applied the extraction principle of sluicing sand over mercury. Two men at a time would wash the earth down with high pressure hoses, with two ten-hour shifts a day. In the past few years, however, Esteban had engaged with a regional university who helped design new sluices, allowing him to work without mercury. The university facilitated the acquisition of a large trommel (a larger version of the one shown here in Figure 2). A trommel is a rotating perforated drum for a secondary gravitational extraction of the heavy sand caught in the sluices. Mercury is still used for the final extraction. However, additional safety measures have been added and the operation is carried out in a controlled environment. For example, fume hoods extract mercury vapour and breathing masks and other protective equipment are used (Figure 5).

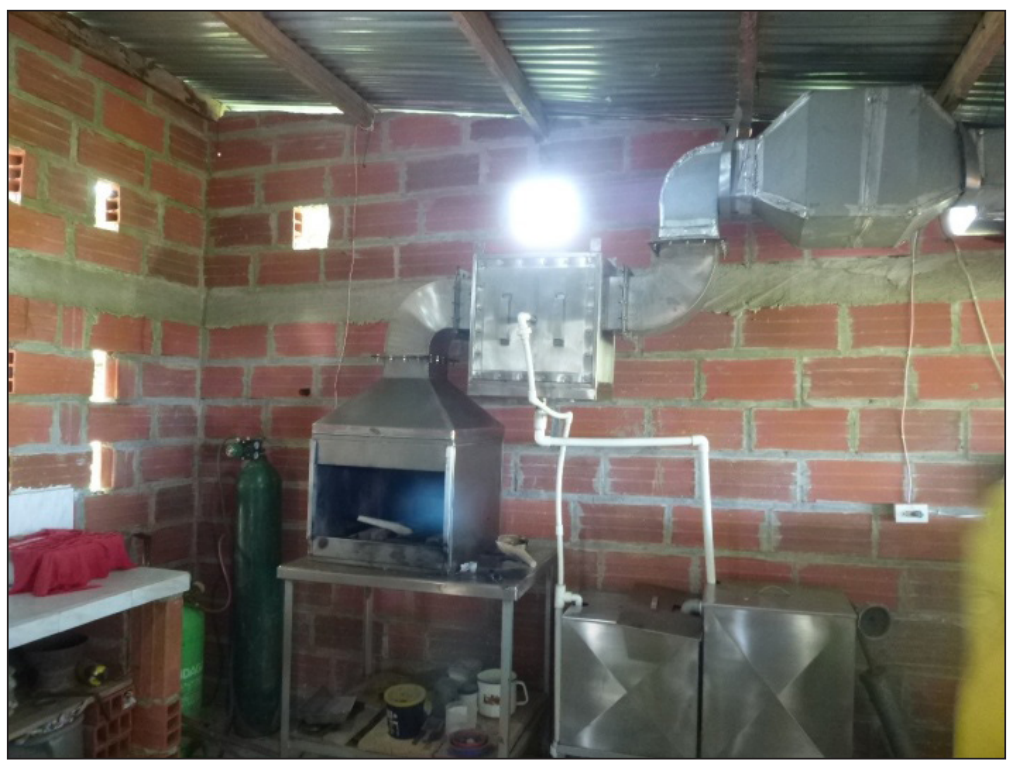

Figure 5. The extraction workshop: mercury-gold amalgam is refined under this fume hood. 
Esteban and Miguel spoke constantly about change in mining, but in different terms than Carlos. While Carlos was troubled by the legal issues of his informal mining, his primary concern lay with the environment. Esteban and Miguel were also concerned for the environment, but this was strongly fixed within a wider vision of 'responsible mining' which included all environmental aspects (mercury reduction, but also reforestation), legality, labour rights, and business capability. Previously, mercury had allowed them relative efficiency for minimum expenditure, much as Carlos had experienced. However, they had come to experience a range of barriers related to informality, or the ability to operate effectively without a mining title. Their use of mercury was not simply coincidental to informality, but co-constitutive of their informality.

Firstly, the crackdown on informal miners was a shock. They saw themselves as hard working men, who had mining in their blood. They were providers for their families, and contributors to the nation. They were dismayed that they may now be considered criminals. They introduced me to the president of their miners' association, Ramiro Restrepo, who asserted this point even more strongly, saying miners wanted to establish their legitimacy by eliminating mercury and establishing environmentally sound mining practices. Identity aside, the scale of Esteban and Miguel's operations meant they had to formalise to survive. As they had a large and visible mine rather than a nomadic dredge, they could not move their operations in order to hide from the authorities.. Finally, to grow their mine, they needed more capital than what they could borrow through informal channels, and they wanted a mining title to provide more security before making a larger investment.

Earlier attempts at formalisation by obtaining a legal mining title had been stymied. They had applied for a title over five years ago and had made significant investments in environmental assessments and processual changes to be eligible for this title, but it still had not been awarded. The problem was nomadism. They needed to prove five years of continuity on their site to be eligible for a title. While they had been mining the same river bed for thirty years, which they treated as a single mining site, the river bed crossed a number of legal land boundaries. As the mining front had crossed one of these boundaries less than five years ago, they were not deemed to have continually operated the same mining site. ${ }^{5}$ If they could obtain a title, they would move into a new operating environment where operating without mercury became effective. In this new environment, mercury's absence can generate a new, responsible form of mining, as well as a new type of citizen: 'the responsible miner.' Currently, Esteban and Miguel are stuck in limbo. Their mine is a limited liability company which pays tax. It is regularly inspected by government environmental assessors, it 
complies with employment law, it partners with regional universities, and yet it is, by the letter of the law, considered an illegal operation until a mining title is received.

THE GOLD PROCESSING WORKSHOP (ENTABLE) OF SEGOVIA: THE HEART OF AN ENTANGLEMENT

In Segovia, all the mining is hard rock, carried out in subterranean tunnels, and of quite a different character to placer mining. There I (Thomas) was introduced to Santiago, the owner of a gold processing workshop (colloquially known as an entable) where miners would process their gold. Santiago said that most miners were simply not interested in the issues that I was talking about, and that they thought of nothing but women, alcohol and gambling. Santiago made it his mission to introduce me to such miners. The miners who I had spoken to up until then were those engaging with the formal sector and the major changes occurring. In this case, Santiago introduced me to a miner named Juan, who I met in a shabby casino, who, on first impression, appeared to embody this unflattering stereotype. However, this first impression proved deceiving. While Juan may have had his share of vices, he identified as a traditional miner, took pride in his profession, and spoke of the issues facing mining in a knowledgeable and managerial fashion. He had spent his entire life mining in the region, as had several generations of his family. He was, however, ambivalent about mercury's toxicity, while Santiago flatly asserted that it was safe.

Juan is a hard rock miner, cutting and blasting underground tunnels into the rock to access veins of gold, the standard mode of mining in Segovia. Juan described hard rock mining as a subsistence activity, in that miners worked for their daily bread, and did not operate in a 'business-like' manner:

The miner is proud of his work ... I as a miner, I might find, perhaps five grams of gold in a vein, after one or two years working the tunnel, without pay, obtaining food in whatever manner. Then I arrive at the vein. We arrive at the vein, and then it's a song.

Juan described a riskier and more processual type of mining than the steady alluvial mining of Carlos, Esteban and Miguel. Juan went on to describe that what he took pride in was not just the mining, but the entire process of extraction and processing: from mining the gold bearing rocks, grinding them, amalgamating the gold, and watching the amalgam being burned before the elusive gold is finally revealed. This is a process that is practiced with materials and that is sensorially experienced, and one that extends far beyond the mine, 
to entables like Santiago's.

These entables are the primary site of mercury use in hard rock gold mining. In Santiago's entable, like many others, the process is divided into two stages. In the first stage, the miners themselves grind their ore with mercury in ball mills, or cocos (Figure 6, Figure 7), smashing the rocks and exposing the gold which becomes trapped in the mercury: a four to eight hour process. This soft amalgam is then washed (with bare hands), to produce a hardened amalgam (Figure 8). Juan would take this amalgam to a local gold buying shop, but he would not pay Santiago for the service. ${ }^{6}$

As payment, the miners would leave all the leftover tailings in the cocos. The mercury process is relatively inefficient in terms of extraction, recovering as little as 30\% of the gold (Cordy et al. 2011; Veiga et al. 2014). Santiago would then perform a cyanide extraction on these tailings over four to five days in a series of concrete pools (Figure 9) or pits dug into the older tailings (Figure 10). Santiago did not let me see the process of extracting gold from cyanide. However, other sources describe a zinc and acid based extraction which releases

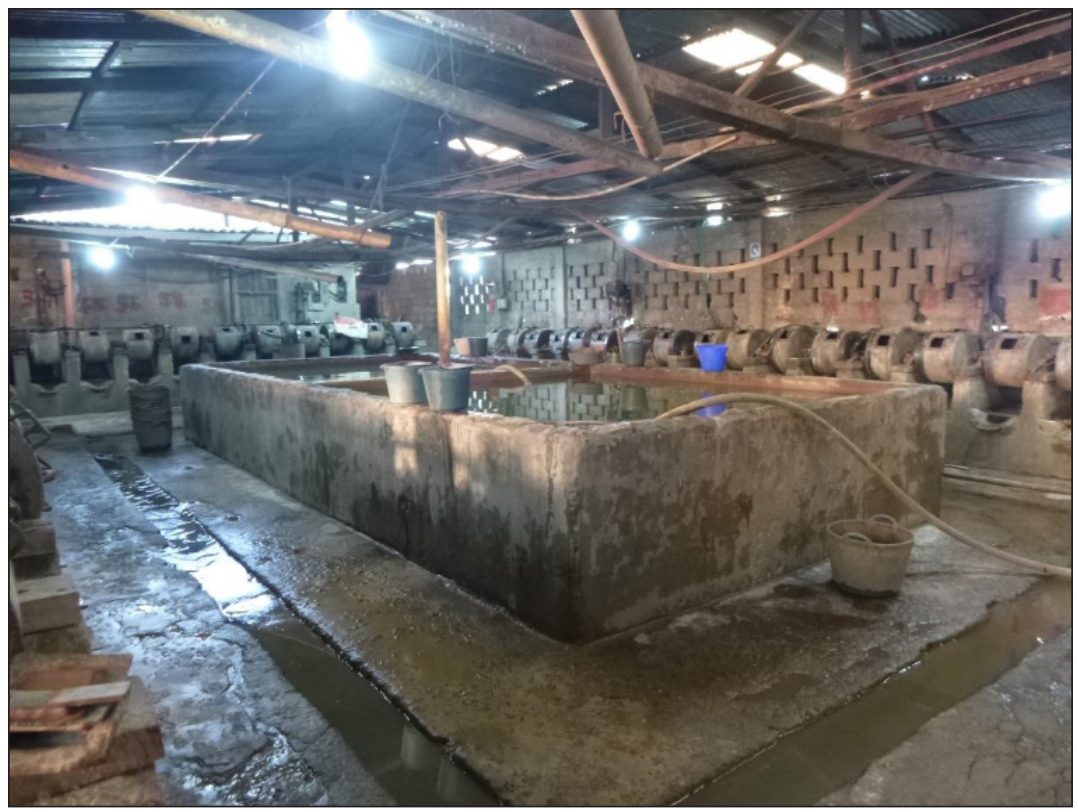

Figure 6. The ball mills in Santiago's workshop. 
Article $\cdot$ Robertson \& Farrelly

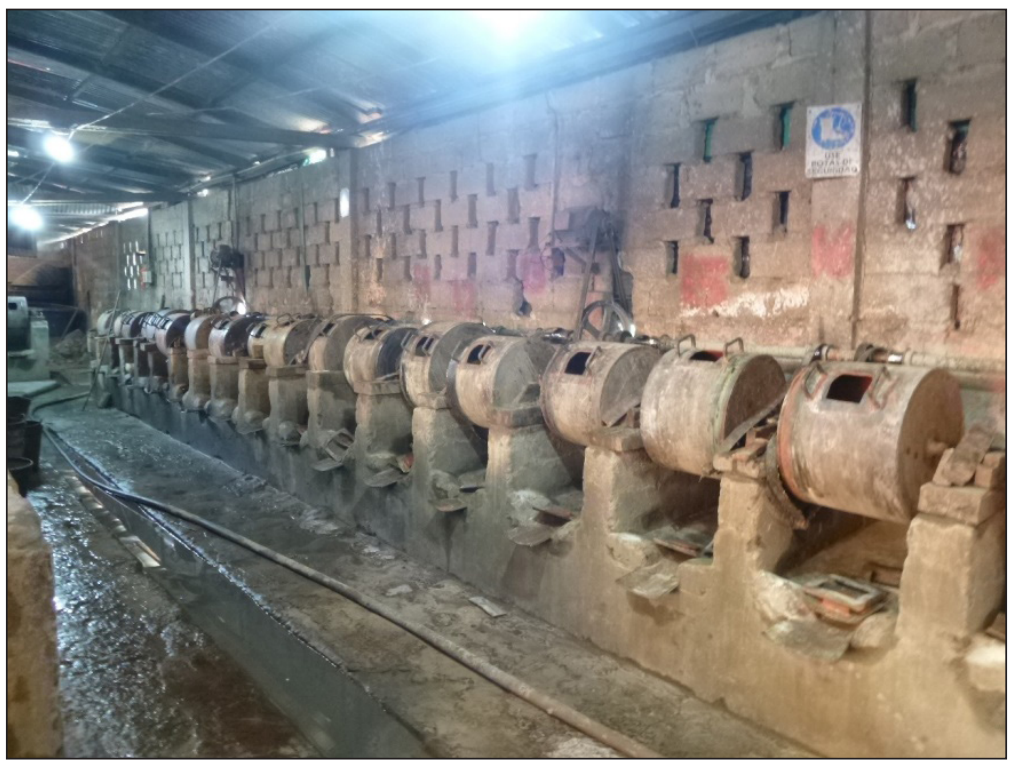

Figure 7. A closer view of the ball mills.

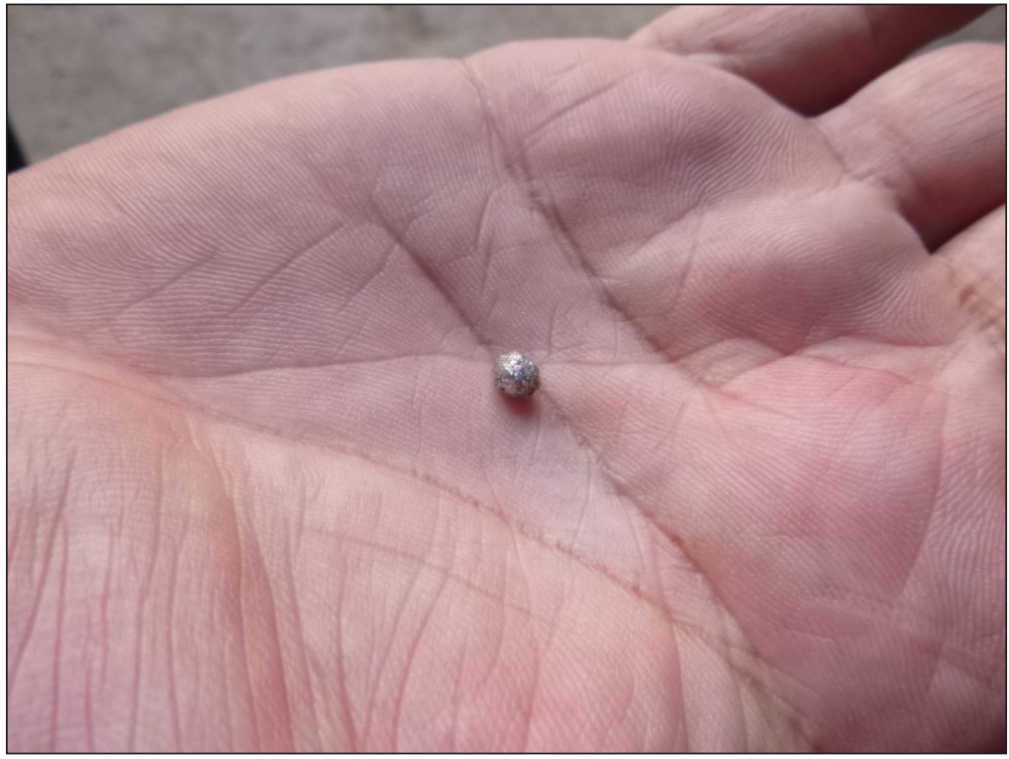

Figure 8: A disappointingly small ball of mercury-gold amalgam. 


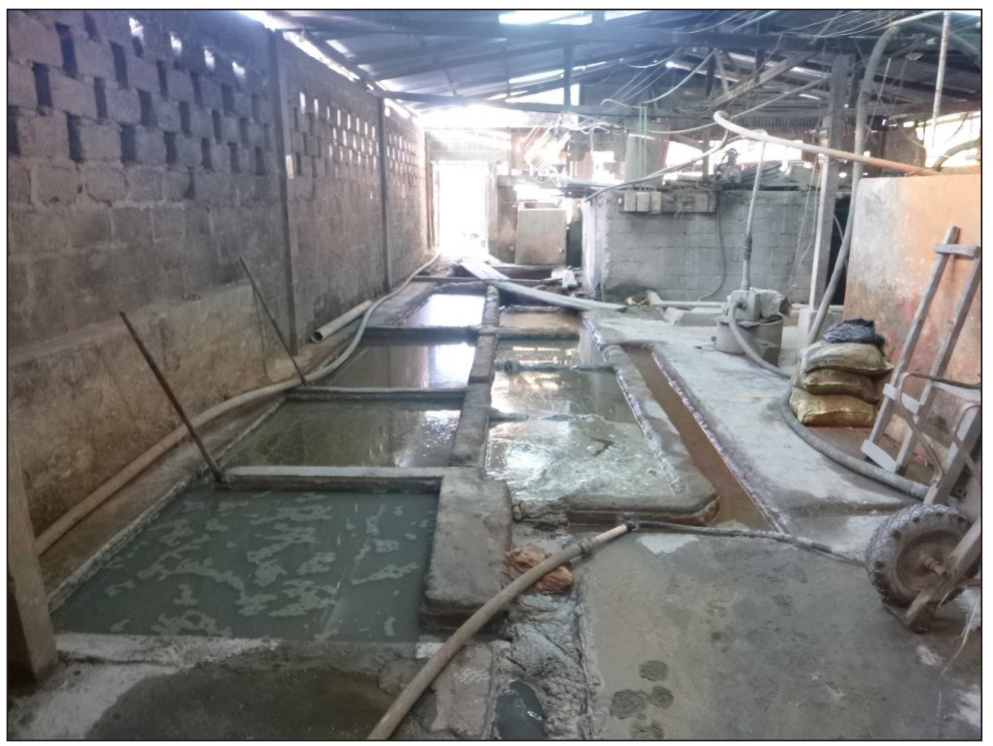

Figure 9: Cyanide extraction in concrete pools. The planks to the rear are used as a walkway over the cyanide.

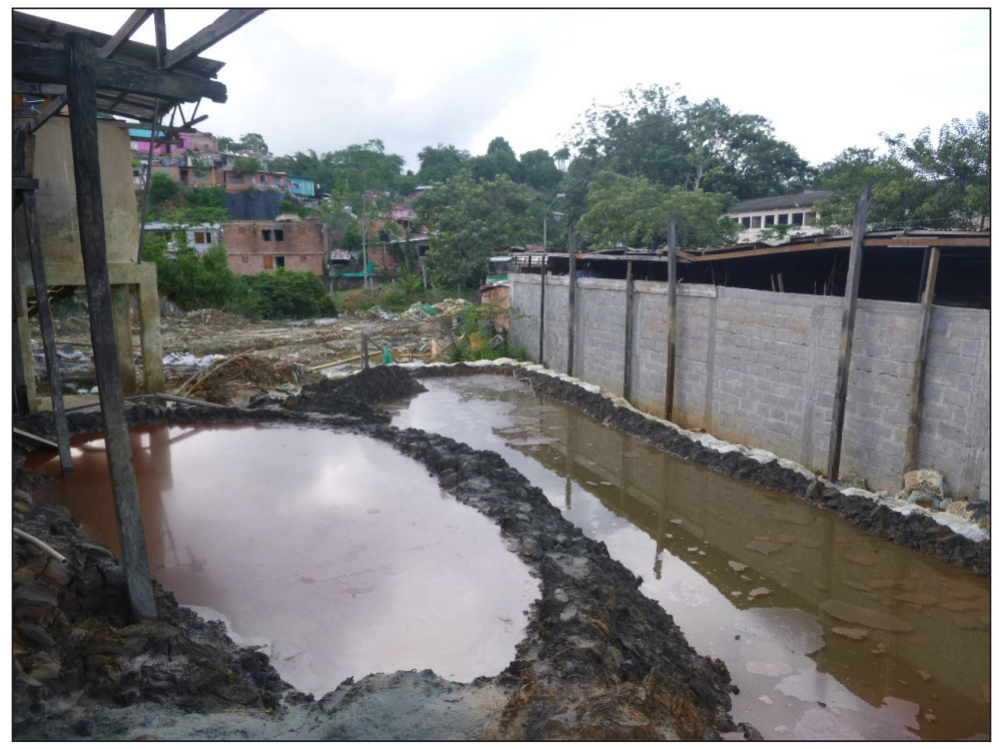

Figure 10: Cyanide pools in the tailings outside. The visible buildings are residential. 
heavy metals into the environment (Cordy et al. 2011). The cyanide typically recovers $80 \%$ of the gold present in the tailings, or around $55 \%$ of the gold in the ore brought by the miners (García et al. 2015), while the waste was directed into a nearby stream, rendering it completely lifeless.

This entanglement of miners, workshop owners, and materials has produced a system which is highly effective in this context. As the miners are solely responsible for the mercury extraction, Juan has confidence in the system because it allows no possibility of being cheated. Another benefit is that the whole ore amalgamation is a relatively quick process. This suits miners' lifestyles, as Juan told me how he and most of the miners from Segovia lived around the mines, only coming into town for a few days to visit their families or socialise and carry out their extractions. Finally, Juan strongly emphasised how much pride he took in taking the ore from the mountain and processing it to form pure gold, even joking that there was a religious aspect to this, akin to transubstantiation or gold worship.

The mercury/cyanide extraction system used in the entables also has economic implications that make it well-suited to informal small-scale mining. Juan was able to extract gold without any level of capital expenditure or expense, and he made it very clear that he had neither the desire nor capability to invest tens of thousands of dollars in a cyanide plant to carry out his own week-long extractions. He also lacked the trust in the entable owners to hand the ore over to them to complete a full cyanide extraction. The two-stage mercury/cyanide extraction model used in the entables meant that Juan could work without making investments in assets that would always be at risk of police seizure. When he did need credit, particularly to buy food and cover living expenses while constructing a tunnel, he borrowed from Santiago who was more than happy to loan to miners, both for the interest on the loan and the guarantee of future custom. This informal economy is effective and is based around mercury. Thus, mercury can be seen as generative of this type of mining and the informal economic system best suited to its use in ASGM.

FORMALISATION THROUGH SUBCONTRACTING: A MATERIAL-POLITICAL CONFIGURATION

The success in mercury reduction in Antioquia has been greatly assisted by miners in Segovia using the cyanide plant ${ }^{7}$ of the Gran Colombia Gold Company (GCG), a Canadian multinational mining firm (García et al. 2015). In this arrangement, miners sign contractual agreements with GCG allowing them to mine specific areas within GCG's mining title. This is effectively formalisation, 
with the subcontracts functioning as a form of mining title. A third of mines in the area were able to formalise in this manner. The other two thirds of the miners were forcibly expelled, as without subcontracts, they were framed as illegal operators. Juan had been pushed into such a relationship previously, but it had not worked out well, as the increase in costs without an increase in revenue made his operation non-viable. Interestingly, the legislation allowing for this arrangement was focused on mercury, not mining titles. The title holder is legally responsible for all activity within the title, including compliance with environmental laws, health and safety, employment law, taxation and mercury use. However, they can expect financial recompense from the miners. This arrangement has proven profitable for GCG, and in $2014,78 \%$ of the gold the company extracted in Segovia came from subcontracted miners rather than their own operation (GCG 2015, 4).

While effective in terms of mercury reduction and formalisation, the subcontracts are problematic in other regards. Juan's family had mined in the region for generations, and contested the idea that GCG, a recent arrival, should have the primary right to mine. The shift to formal mining also represents what Juan saw as a fundamentally different mode of mining: 'The miner has to create a company [to work with GCG], but it's not the culture of this region. Here the miner works very artisanally. He works for his daily bread'. The conception of this new mining as entrepreneurial was not based on financial arrangements and profits, but on engaging with the significant levels of environmental and safety regulations required. This engagement led to significantly increased expenses while GCG received up to $45-50 \%$ of the gold. This was an arrangement Juan considered profoundly unjust.

You have to enter into business with Sandor Capital [GCG's subsidiary]. Sandor Capital says to you that you can work under these conditions. The ore has to go to Sandor's [cyanide] plant to process the mineral. But the mining happens in an area that belongs to us, and we have to pay them. We take the big risks. And you have to pay all the expenses and everything, while they are taking $45-50 \%$ of all the gold.

Also significant here is that the arrangement is enforced through the absence of mercury/presence of cyanide. By requiring miners to take their ore to their cyanide plant, GCG is able to guarantee both mercury elimination and their share of the profits. The cyanidation is a batch extraction process whereby different miners' ore is processed in one batch, rather than individually. Miners bring their ore and GCG takes samples from the ore to determine gold concentrations. The miner payouts are based on these concentration assays. Juan had no faith 
in this process, believing strongly that he was regularly cheated through low estimates. These are allegations which I (Thomas) also heard mentioned from some professional mining engineers. Furthermore, his modes of credit were cut as he ceased his relationship with the entable. No alternative presented itself to help with his increased capital costs. This apparently unjust arrangement was brought about not through entanglements with mercury, but with mercury's absence (Farrelly, Stewart-Withers, and Dombroski 2014; Meyer 2012). While subcontracting relationships have been a highly effective mercury elimination solution (García et al. 2015), following the causes and effects of mercury's absence highlights the political imbalances associated with this programme.

\section{CONCLUSION}

By using a 'follow the thing' approach to generate an ethnography of entanglements we have begun to look at the relationship between miners and mercury in a different way. The insights gleaned through this ethnographic research deny the possibility of distinct sociality and materiality, and emphasise the highly inter-relational nature of these categories. To highlight the significance of what we have discussed here, we wish to juxtapose our model with two alternate perspectives of artisanal mining. The first is a flow chart of the gold extraction process in entables in Antioquia (Figure 11), produced by Cordy et al. $(2011,157)$.

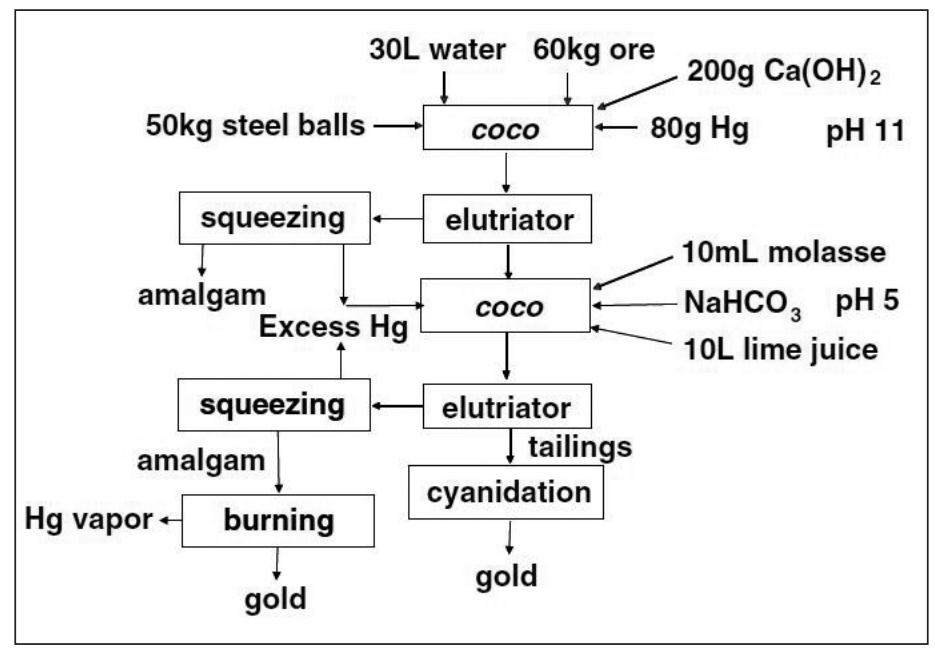

Figure 11. 'Flow sheet of a typical whole ore amalgamation in cocos'. Reproduced from Cordy et al. $(2011,157)$ 
This diagram provides a detailed description of the physical process of gold extraction. However, it is reductive rather than holistic, in that people are absent along with social, economic and political relations. The second example is a hypothetical ethnography of miners, in which there is an analytical focus on the society and culture of miners, perhaps focusing on salient aspects such as masculinity, ritual, or ethnicity, providing rich insight into the worldview of miners. Variations of these two examples are the approaches that dominate the literature, and while valuable, the analysis they provide is either incomplete or they provide a reductionist explanation of the complex whole.

What we have tried to describe here is an ethnography of entanglements, in which both miners and materials are important, but in which the relationship is prioritised over each contributor to the relationship. What new understandings can come from such an approach? Firstly, we can start by saying that mercury pollution is not the result of purely technical factors; neither is it the result of purely social factors. It is a phenomenon which emerges from the entanglement of people and materials. ASGM in Colombia has been described as small-scale, nomadic, and informal, often with limited capital investments, (Cordy et al. 2013; Cordy et al. 2011; Echavarria 2014; García et al. 2015; Urán 2013). As these qualities are all tied up with the presence of mercury, it is also possible to state that ASGM in Colombia is an emergent phenomenon of an entanglement of mercury with a range of human and nonhuman actors, or that mercury is coconstitutive of particular modes of mining.

An ethnography of entanglements approach also generates new understandings of the implications of disentangling mercury from ASGM. Disentangling mercury is neither simple nor politically neutral. In the case of Carlos, it has involved engaging new actors, new types of knowledge, and dealing with fixed plant, arrangements which conflict with the context in which he operates, and are only sustained through his environmental consciousness and the precarious intervention of an NGO. In the case of Esteban and Miguel, disentangling themselves from mercury has occurred alongside a shift to a larger, more entrepreneurial and responsible mining. They face continued challenges shifting from informality to formality. This is a shift that is intimately linked to eliminating mercury as mercury's absence has become a necessary tool for establishing a new legal and responsible type of mining.

For Juan, eliminating mercury seems only possible through entering into an agreement with a large scale, foreign-owned mining company. This relationship did not acknowledge his traditional right to mine, and he considered it economically exploitative. With the failure of this relationship, he has to con- 
tinue using mercury, but now struggles to reconcile this use with his image of a traditional miner. Disentangling mercury brings about new political and economic relationships, enforced through mercury's absence. For Santiago, disentangling mercury means the end of his business.

Following mercury has helped us in creating an ethnography of entanglements, which in turn has assisted in destabilising the idea of the existence of discrete 'social' and 'material' dimensions to mining, and in considering what a more inter-relational approach might look like. Beyond the implications for mining studies, such an approach offers potentials for anthropology at a time when ethnography is at a crossroads. With increasing pressure to reconsider what ethnography is or is not, and a research environment which often restricts time frames, we hope this work contributes to a wider discussion of what ethnography can look like and what it can contribute.

\section{ACKNOWLEDGEMENTS}

This research was funded through a Ryoichi Sasakawa Young Leaders' Fellowship Fund grant.

\section{NOTES}

1 Thomas Robertson is a researcher with interests in political ecology, the extractive industries and society, interdisciplinary research and labour unionism. A graduate from Massey University, Thomas holds an MA in Social Anthropology, and is a Fellow of the Ryoichi Sasakawa Young Leaders Fellowship Foundation. Thomas is currently working as a researcher in the Australian union movement.

Email: thomas@trobertson.co.nz

2 An environmental anthropologist and political ecologist, Dr Trisia Farrelly works with a wide range of 'knowledgeable publics' to democratise the science and policy of environmental sustainability. Dr Farrelly is Co-Founder and Trustee of the New Zealand Product Stewardship Council; Co-Director of Massey University's Political Ecology Research Centre; Co-Founder of environmental lobby group, Carrying Our Future; a founding member of progressive political organisation, New Zealand Alternative; and Fellow of the Royal Geographical Society and the Ryoichi Sasakawa Young Leaders Fellowship Foundation.

Email: T.Farrelly@massey.ac.nz

3 In 2015, Massey University, New Zealand introduced a 180 credit Master of Arts, which included three semesters of full time study over 12 months (including 
the summer semester). 120 credits of this was the thesis. This limits the time for fieldwork, and even the three months taken here was ambitious.

4 Gold is separated because it is heavier than sand.

5 Hernando de Soto's formalisation has been common in the literature of mining, and focuses on the idea that formalisation should involve the recognition of preexisting customary rights (Siegel and Veiga 2009). However, this example draws attention to the unrecognized difference between the way formal and informal property rights operate in terms of the occupation of space.

6 Earlier studies in Antioquia reported that many workshops would charge miners a nominal fee of $\$ 0.50$ to $\$ 1.00$ USD (Cordy et al. 2011, 155).

7 Cyanide is commonly recommended as a preferable alternative to mercury, although, as it is also toxic, it is an imperfect solution (Davies 2014; UNEP 2012; Veiga et al. 2009). Cyanide is an organic compound which can break down with the correct treatment (Johnson 2015), whereas mercury is an element and will not break down. The majority of the problems with cyanide arise from its mismanagement, rather than from inherent problems with its correct management (Hilson and Monhemius 2006), whereas mercury cannot be satisfactorily managed.

\section{REFERENCES}

Appadurai, Arjun. 1996. The Social Lives of Things: Commodities in Cultural Perspective. New York: Cambridge University Press.

Ballard, Chris, and Glenn Banks. 2003. 'Resource Wars: The Anthropology of Mining. Annual Review of Anthropology 32: 287-313.

Barad, Karen. 2007. Meeting the Universe Halfway: Quantum Physics and the Entanglement of Matter and Meaning. Durham, NC: Duke University Press.

Barry, Mamadou. 1996. Regularising Informal Mining: A Summary of the Proceedings of the International Roundtable on Artisanal Mining. Washington D.C.: The World Bank Industry and Energy Department.

Bryceson, Deborah Fahy, Jesper Bosse Jønsson, and Hannelore Verbrugge. 2013. 'Prostitution or Partnership?: Wifestyles in Tanzanian Artisanal Gold-mining Settlements. Journal of Modern African Studies 51 (1):33-56. 
Clifford, Martin J. 2014. 'Future Strategies for Tackling Mercury Pollution in the Artisanal Gold Mining Sector: Making the Minamata Convention Work'. Futures $62(\mathrm{~A}): 106-112$.

Cohen, Roseann. 2014. 'Extractive Desires: The Moral Control of Female Sexuality at Colombia's Gold Mining Frontier'. The Journal of Latin American and Caribbean Anthropology 19 (2):260-279.

Connolly, W.E. 2013. 'The "New Materialism" and the Fragility of Things'. Millenium - Journal of International Studies 41:399-412.

Cordy, Paul, M.M. Veiga, Ben Crawford, Oseas Garcia, Victor Gonzalez, Daniel Moraga, Monika Roeser, and Dennis Wip. 2013. 'Characterization, Mapping, and Mitigation of Mercury Vapour Emissions From Artisanal Mining Gold Shops'. Environmental Research 125: 82-91.

Cordy, Paul, Marcello M. Veiga, Ibrahim Salih, Sari Al-Saadi, Stephanie Console, Oseas Garcia, Luis Alberto Mesa, Patricio C. Velásquez-López, and Monika Roeser. 2011. 'Mercury Contamination From Artisanal Gold Mining in Antioquia, Colombia: The World's Highest Per Capita Mercury Pollution'. Science of the Total Environment 410:154-160.

Cuvelier, Jeroen. 2014. 'Work and Masculinity in Katanga's Artisanal Mines'. Africa Spectrum $49(2): 3-26$.

Davies, George R. 2014. 'A Toxic Free Future: Is There a Role for Alternatives to Mercury in Small-scale Gold Mining?' Futures 62 (A):113-119.

Drace, Kevin, Adam M. Kiefer, Marcello M. Veiga, Matt K. Williams, Benjamin Ascari, Kassandra A. Knapper, Kaitlyn M. Logan, Vanessa M. Breslin, Ashley Skidmore, Daniel A. Bolt, Grant Geist, Lorlyn Reidy, and James V. Cizdziel. 2012. 'Mercury-free, Small-scale Artisanal Gold Mining in Mozambique: Utilization of Magnets to Isolate Gold at Clean Tech Mine'. Journal of Cleaner Production 32: 88-95.

Echavarria, C. 2014. 'What is Legal? Formalising Artisanal and Small-scale Mining in Colombia'. London, United Kingdom; Envigado, Colombia: International Institute for Environment and Development; Sustainable Markets Group; The Alliance for Responsible Mining.

Eftimie, Adriana, Katherine Heller, John Strongman, J.J. Hinton, Kuntala Lahi- 
ri-Dutt, and Nellie Mutemeri. 2012. Gender Dimensions of Artisanal and Small-scale Mining: A Rapid Assessment Toolkit. In Gender Action Plan. Washington D.C., USA: The World Bank Group's Oil, Gas, and Mining Unit, Sustainable Development Network, Sustainable Energy Department.

El Congreso de Colombia. 2013. Ley No. 1658. Bogotá, Colombia: Author.

Farrelly, Trisia, Rochelle Stewart-Withers, and Kelly Dombroski. 2014. "Being there": Mothering and Absence/Presence in the Field'. Sites 11 (2):25-56.

García, Oseas, Marcello M. Veiga, Paul Cordy, Osvaldo E. Suescún, Jorge Martin Molina, and Monika Roeser. 2015. 'Artisanal Gold Mining in Antioquia, Colombia: A Successful Case of Mercury Reduction' Journal of Cleaner Production 90:244-252.

GCG. 2015. Management's Discussion and Analysis for the Year Ended December 31, 2014. Gran Colombia Gold Corporation.

Giraldo-Ramírez, Jorge , and Juan Carlos Muñez-Mora. 2012. Informalidad e Ilegalidad en la Explotación del oro y la Madera en Antioquia. Medellin, Colombia: Universidad Eafit, Proantioquia.

Golub, Alex. 2014. Leviathans at the Gold Mine: Creating Indigenous and Corporate Actors in Papua New Guinea. Durham, NC: Duke University Press.

Grätz, Tilo. 2004. 'Friendship Ties Among Young Artisanal Gold Miners in Northern Benin (West Africa)'. Africa Spectrum 39 (1):95-117.

- 2009. 'Moralities, Risk and Rules in West African Artisanal Gold Mining Communities: A Case Study of Northern Benin'. Resources Policy 34 (1/2):12-17.

Güiza, L., and J.D. Aristizábal. 2013. 'Mercury and Gold Mining in Colombia: A Failed State. Universitas Scientiarum 18 (1):33-49.

Heemskerk, Marieke. 2002. 'Livelihood Decision Making and Environmental Degradation: Small-scale Gold Mining in the Suriname Amazon'. Society and Natural Resources 15 (4):327-344.

Hilson, Gavin. 2006. 'Abatement of Mercury Pollution in the Small-scale Gold Mining Industry: Restructuring the Policy and Research Agendas'. Science of the Total Environment $362(1 / 3): 1-14$. 
Hilson, Gavin, and A.J. Monhemius. 2006. 'Alternatives to Cyanide in the Gold Mining Industry: What Prospects for the Future?' Journal of Cleaner Production $14(12 / 13): 1158-1167$.

Hilson, Gavin, and Sandra Pardie. 2006. 'Mercury: An Agent of Poverty in Ghana's Small-scale Gold-mining Sector?' Resources Policy 31(2):106-116.

Hinton, J.J., M.M. Veiga, and C. Beinhoff. 2003. 'Women and Artisanal Mining: Gender Roles and the Road Ahead'. In The Socio-economic Impacts of Artisanal and Small-scale Mining in Developing Countries, edited by Gavin Hilson. Netherlands: A.A. Balkema, Swets Publishers.

Hinton, J.J., M.M. Veiga, and A.T. C. Veiga. 2003. 'Clean Artisanal Gold Mining: A Utopian Approach?' Journal of Cleaner Production 11 (2): 99-115.

Hockey, Jenny, and Martin Forsey. 2012. 'Ethnography is Not Participant Observation: Reflections on the Interview as Participatory Qualitative Research'. In The Interview: An Ethnographic Approach, edited by J. Skinner, 69-87. London, UK: Bloomsbury.

ILO. 1999. Social and Labour Issues in Small-Scale Mines: Report for Discussion at the Tripartite Meeting on Social and Labour Issues in Small-scale Mines. Geneva, Switzerland: International Labour Organisation.

Jacka, Jerry K. 2015. Alchemy in the Rain Forest: Politics, Ecology, and Resilience in a New Guinea Mining Area, New ecologies for the twenty-first century. Durham, NC: Duke University Press.

Johnson, Craig A. 2015. 'The Fate of Cyanide in Leach Wastes at Gold Mines: An Environmental Perspective'. Applied Geochemistry 57:194-205.

Jønsson, Jesper Bosse, Elias Charles, and Per Kalvig. 2013. 'Toxic Mercury Versus Appropriate Technology: Artisanal Gold Miners' Retort Aversion'. Resources Policy 38 (1): 60-67.

Lamborg, Carl H., Chad R. Hammerschmidt, Katlin L. Bowman, Gretchen J. Swarr, Kathleen M. Munson, Daniel C. Ohnemus, Phoebe J. Lam, Lars-Eric Heimburger, Micha J.A. Rijkenberg, and Mak A. Saito. 2014. 'A Global Ocean Inventory of Anthropogenic Mercury Based on Water Column Measurements'. Nature 512 (7512): 65-69. 
Latour, Bruno. 2007. 'Reassembling the Social: An Introduction to Actor-networktheory'. Clarendon Lectures in Management Studies. Oxford; New York: Oxford University Press, 2007.

Marcus, George E. 1995. 'Ethnography in/of the World System: The Emergence of Multi-sited Ethnography'. Annual Review of Anthropology 24:95-117.

Meyer, M. 2012. 'Placing and Tracing Absence: A Material Culture of the Immaterial'. Journal of Material Culture 17 (1):103-110.

Mintz, Sidney. 1985. Sweetness and Power: The Place of Sugar in Modern History. New York: Penguin Books.

National Geographic. n.d. '[Map of Fieldwork Locations in Antioquia, Colombia: Created with National Geographic MapMaker Interactive]'. Accessed February 2o. http://mapmaker.nationalgeographic.org/

Okely, J. 2015. 'Dialogues with Anthropologists: Where Interviews Become Relevant'. In Extraordinary Encounters: Authenticity and the Interview, edited by K. Smith, J. Staples and N. Rapport, 128-156. New York: Berghahn Books.

Olivero, Jesús, Claudia Mendonza, and Judith Mestre. 1995. 'Mercurio en Cabello de Diferentes Grupos Ocupacionales en una Zona de Minería Aurifera en el Norte de Colombia. Revista de Saúde Pública 29 (5):376-379.

Rivera-Sotelo, Aída Sofía. 2012. Interrogating Sustainable Development: A Case Study of Large-scale Mining in Colombia. Master's thesis, Program of Cultural Studies, Queen's University.

SDC. 2016. Professional Artisanal Mining in Mongolia: A Sustainable Artisanal Mining Project Success Story. Switzerland: Swiss Agency for Development and Cooperation.

Seccatore, Jacopo, Marcello Veiga, Chiara Origliasso, Tatiane Marin, and Giorgio De Tomi. 2014. 'An Estimation of the Artisanal Small-scale Production of Gold in the World'. The Science of the Total Environment 496: 662-667.

Serje de la Ossa, Margarita Rosa. 2005. El Revés de la Nación: Territorios Salvajes, Fronteras y Tierras de Nadie. Bogotá, Colombia: Universidad de los Andes, Facultad de Ciencias Sociales-Ceso y Departamento de Antropología. 
Siegel, Shefa, and M.M. Veiga. 2009. 'Artisanal and Small-scale Mining as an Extralegal Economy: De Soto and the Redefinition of "Formalization"'. Resources Policy 34 (1/2):51-56.

Soemarwoto, Rini, and Roy Ellen. 2010. 'Gold Mining and Changing Perceptions of Risk in West Java'. Human Organization 69 (3):233-241.

Spiegel, Samuel, Susan Keane, S.M. Metcalf, and M.M. Veiga. 2015. 'Implications of the Minamata Convention on Mercury for Informal Gold Mining in SubSaharan Africa: From Global Policy Debates to Grassroots Implementation?' Environment, Development and Sustainability 17 (4):765-785.

Spiegel, Samuel, Susan Keane, S.M. Metcalf, M.M. Veiga, and Annalee Yassi. 2014. 'The Minamata Convention on Mercury: Time to Seek Solutions with Artisanal Mining Communities'. Environmental Health Perspectives 122 (8):A2O3A204.

Stewart-Withers, R., G. Banks, A. McGregor, and L. Meo-Sewabu. 2014. 'Qualitative Research' In Development Fieldwork: A Practical Guide, edited by Regina Scheyvens, 59-80. London: Sage Publications.

Taussig, Michael T. 1980. The Devil and Commodity Fetishism in South America. Chapel Hill, NC: The University of North Carolina Press.

-2004. My Cocaine Museum. Chicago, IL: University of Chicago Press.

Tubb, D. 2014. Gold in the Chocó, Colombia. PhD Dissertation, Department of Anthropology and Sociology, Carleton University.

- 2015. 'Muddy Decisions: Gold in the Chocó, Colombia'. The Extractive Industries and Society $2(4): 722-733$.

UNEP. 2006. Summary of Supply, Trade and Demand Information on Mercury. Geneva, Switzerland: United Nations Environmental Programme.

- 2012. Reducing Mercury Use in Artisanal and Small-scale Gold Mining: A Practical Guide. United Nations Environmental Programme.

- 2013. Global Mercury Assessment 2013: Sources, Emissions, Releases and Environmental Transport. Geneva, Switzerland: United Nations Environmental Programme. 
Urán, Alexandra. 2013. 'La legalización de la Minería a Pequeña Escala en Colombia’. Letras Verdes 14:255-283.

Veiga, Marcello M. 2015. 'Roundtable discussion'. SIPS: Meech International Symposium, Antalya, Turkey.

Veiga, Marcello M., Gustavo Angeloci-Santos, Michael Hitch, and Patricio Colon Velasquez-Lopez. 2014. 'Processing Centres in Artisanal Gold Mining'. Journal of Cleaner Production 64:535-544.

Veiga, Marcello M., and R.F. Barker. 2004. Protocols for Environmental and Health Assessment of Mercury Released by Artisanal and Small-scale Gold Miners. Vienna, Austria: unido Global Mercury Project.

Veiga, Marcello M., P.A. Maxson, and Lars D. Hylander. 2006. 'Origin and Consumption of Mercury in Small-scale Gold Mining. Journal of Cleaner Production $14(3 / 4): 436-447$.

Veiga, Marcello M., D. Nunes, B. Klein, J.A. Shandro, P.C. Velasquez, and R.N. Sousa. 2009. 'Mill Leaching: A Viable Substitute for Mercury Amalgamation in the Artisanal Gold Mining Sector?' Journal of Cleaner Production $17(15): 1373-1381$.

Verbrugge, Boris. 2015. 'Undermining the State?: Informal Mining and Trajectories of State Formation in Eastern Mindanao, Philippines'. Critical Asian Studies $47(2): 177-199$. 